\title{
Novel tuffite/Fe-Cu oxides nanocomposite with functionality for dye removal in aqueous solution
}

\author{
Alien Blanco-Flores ${ }^{\mathrm{a}, \mathrm{b}, *}$, Victor Sánchez-Mendieta ${ }^{\mathrm{b}}$, Edith Gutiérrez-Segura ${ }^{\mathrm{b}}$, \\ Alfredo R. Vilchis-Néstor ${ }^{\mathrm{c}}$, Raul A. Morales-Luckie ${ }^{\mathrm{b}}$ \\ a División de Mecánica, Tecnológico de Estudios Superiores de Tianguistenco, Carretera Tenango-Marquesa Km 22, Santiago Tilapa, C.P. 52650, Santiago \\ Tianguistenco, Estado de México, Mexico \\ ${ }^{\mathrm{b}}$ Facultad de Química, Universidad Autónoma del Estado de México, Paseo Colón y Tollocan s/n., C.P. 50000 Toluca, Estado de México, Mexico \\ ' Centro Conjunto de Investigación en Química Sustentable UAEM-UNAM, Carretera Toluca, Atlacomulco Km 14.5, Unidad San Cayetano, C.P. 50200, Toluca, \\ Estado de México, Mexico
}

\section{A R T I C L E I N F O}

\section{Article history:}

Received 30 May 2016

Received in revised form 23 September 2016

Accepted 3 October 2016

Available online 4 October 2016

\section{Keywords:}

Tuffite

Fe-Cu nanoparticles

Nanocomposite

Adsorption

Malachite green

\begin{abstract}
A B S T R A C T
Fe-Cu oxides nanoparticles were embedded on tuffite (TUF) mineral by means of a simple immersion-ion impregnation, followed by a reduction reaction, methodology. TUF/Fe-Cu nanocomposite characteristics were investigated by XRD, TEM, BET, SEM, FT-IR spectroscopy and $\mathrm{pH}_{\mathrm{zpc}}$ method. Fe-Cu nanostructures with mean sizes between 10 and $20 \mathrm{~nm}$ were effectively supported on TUF. Because of its functional properties, the nanocomposite was studied as adsorbent material for the degradation of malachite green (MG) organic dye in aqueous solution. The adsorption kinetic data was well-fitted to pseudo first-order model, indicating physisorption as the main mechanism of adsorption. High $\mathrm{pH}$ and temperature of the solution favored malachite green adsorption. The adsorption process was spontaneous and endothermic. In comparative sorption experiments with different dyes, the nanocomposite showed better removal capacities for cationic and basic than for anionic and acid dyes. Langmuir, Freundlich, LangmuirFreundlich and Temkin models were applied to evaluate the isotherms, resulting in an adsorption capacity of $376.66 \mathrm{mg} / \mathrm{g}$, which is above most of the adsorbent materials so far employed for malachite green degradation in aqueous solution. Therefore, this novel, easy to prepare and low-cost nanocomposite proved to have synergic functionality as an efficient adsorbent material for cationic organic dyes.
\end{abstract}

(c) 2016 Elsevier Ltd. All rights reserved.

\section{Introduction}

The presence of many contaminants in surface water is a real worldwide problem, due to growth population and increase of industrial activities. In this sense, it is necessary to control the water pollution and negative effects of organic and inorganic contaminant [1]. This could be achieved through efficient wastewater treatments, which include the adsorption process. Implementation of adsorption process is generally cheap providing that adsorbent materials are low cost and abundant, like natural minerals such as: zeolites, tuffs and clays, among others [2].

\footnotetext{
* Corresponding author at: División de Mecánica, Tecnológico de Estudios Superiores de Tianguistenco, Carretera Tenango-Marquesa Km 22, Santiago Tilapa, Santiago Tianguistenco 52650, Mexico.

E-mail address: blancoflores81@hotmail.com (A. Blanco-Flores).
}

Recently, nanoparticles have been suggested as efficient, costeffective and environmental friendly alternative specifically metallic nanoparticles, which have relatively higher chemical activity and specificity of interaction [3]. In general, the nanoparticles work in two-fold ways: like adsorbent material and as reducing agent of organic compound, such as dyes. Among other characteristics, they have a high specific surface area. All these aspects could help to improve the technology of actual methods of wastewater treatment. However, these nanomaterials have a disadvantage related to the industrial application since usually they cannot be used by themselves. They can be injected directly into the effluent, however, their separation and recovery after the process is as difficult as expensive. This is the main reason why they should therefore be supported [4]. Researchers have proposed to support nanoparticles on porous, natural or synthetic, materials. This ensures that the separation process will be simple and more easily performed through a filtration operation [5]. Besides, 
researchers have found that an heterogeneous composite has better efficiency than single nanoparticles; in some cases they even develop new synergic properties. Natural materials that have been recently used as low cost effective supports for nanoscale are pillared clays and zeolites such as montmorillonite [6], clinoptilolite [7] and MCM-41 [8] or sewage sludge converted in carbonaceous material [9]. Another low cost adsorbent material is tuff, which is a mineral rich in calcium carbonate. $\mathrm{CaCO}_{3}$ precipitation in tuff produces a vast array of crystal forms; calcite predominates in most instances, followed by aragonite, and to a lesser extent $\mathrm{MgCO}_{3}$. The $\mathrm{SiO}_{2}$ and $\mathrm{MgO}$ are the next most abundant compounds and minor levels of $\mathrm{Al}_{2} \mathrm{O}_{3}$ and $\mathrm{Fe}_{2} \mathrm{O}_{3}$ are also found [10]. These characteristics, which include their availability and abundance, make them low cost adsorbent materials that can be used as templates for nanoparticles.

It is well known that zero-valent iron and iron oxides are effective for organic dyes degradation and improves of biodegradability [11]. The addition of other transition metal, such as copper, may enhance the reactivity of nanoparticles and degradation rates of aquatic contaminants acting through the synergistic effect between bimetallic system and composite [12]. According to this idea, iron-copper oxides nanocomposites have been synthesized to enhance dyes removal $[3,7,13,14]$, but the degradation of organic dyes using $\mathrm{Fe}-\mathrm{Cu}$ nanocomposites remains a scarcely explored area.

Previously, we have studied that the combination between porous materials and metal nanoparticles is one of the most interesting areas of interdisciplinary research in water treatments [7]. The aims of our present study are to synthesize and characterize TUF/Fe-Cu 95/5 wt.\% composite and to evaluate its sorption properties to remove organic dyes, particularly malachite green, from aqueous solution.

\section{Experimental}

\subsection{Materials and reagents}

The tufa (TUF) samples used in this work were collected from the east province Holguín in Cuba. TUF was ground and sieved with a 60 mesh $(0.25 \mathrm{~mm})$ particle size sieve. Malachite green chloride (MG), a basic dye, $\left(\mathrm{CI}=42000\right.$, molecular formula: $\mathrm{C}_{23} \mathrm{H}_{25} \mathrm{~N}_{2} \mathrm{Cl}$, pKa: 6.9 and molecular weight $=365 \mathrm{~g} / \mathrm{mol}$ ). Acid green $25(\mathrm{AG})$, an acid dye, $\left(\mathrm{CI}=61570\right.$, molecular formula: $\mathrm{C}_{23} \mathrm{H}_{18} \mathrm{C}_{1} \mathrm{~N}_{4} \mathrm{Na}_{2} \mathrm{O}_{7} \mathrm{~S}_{2}$, pKa: 6.5 and molecular weight $=622.58 \mathrm{~g} / \mathrm{mol}$ ) and congo red (CR) ( $\mathrm{CI}=22120$, molecular formula: $\mathrm{C}_{32} \mathrm{H}_{22} \mathrm{~N}_{6} \mathrm{Na}_{2} \mathrm{O}_{6} \mathrm{~S}_{2}$, pKa: 5.5 and molecular weight $=696.7 \mathrm{~g} / \mathrm{mol}$ ) (Hycel, México) were used without further treatment. Dyes solutions were prepared by dissolving an appropriate amount of dye in distilled water to obtain a range of concentrations corresponding to $30-120 \mathrm{mg} / \mathrm{L}$ for successive dilutions.

\subsection{Synthesis}

TUF/Fe-Cu(95-5 wt.\%) nanocomposite was obtained by impregnation-chemical reduction synthesis according to the method reported in the literature [13]. $\mathrm{FeSO}_{4} \cdot 7 \mathrm{H}_{2} \mathrm{O}$ and $\mathrm{CuSO}_{4} \cdot 5 \mathrm{H}_{2} \mathrm{O}$ (Fermont, México) were dissolved in distilled water and TUF was added to the reaction medium. The mixture was stirred at room temperature for a fixed contact time. Later the $\mathrm{pH}$ was adjusted $(\mathrm{pH}=7)$ and $\mathrm{NaBH}_{4}$ was added quickly into the mixture. Subsequently, it was filtrated and the composite was washed with distilled water followed by acetone. The product was dried in an oven at $40^{\circ} \mathrm{C}$ and stored in a closed container until further use. After several trials, the best experimental conditions to obtain this composite were: a volume of bimetallic aqueous solution of $100 \mathrm{~mL}$ and a contact time of $60 \mathrm{~min}$.

\subsection{Characterization}

The surface morphology analyses of the composite were performed by scanning electron microscope (SEM) using a JEOL JSM-6510LV SEM microscope operated at $20 \mathrm{kV}$. Samples were fixed on a support with a carbon film and sputter-coated with gold to a thickness of $\sim 200 \AA$. Transmission electron microscopy (TEM) observations were carried out using a JEOL 2100 microscope operated at $200 \mathrm{kV}$ accelerating voltage. For TEM observations, the composite was dispersed by ultrasound in 2-propanol at room temperature $\left(25^{\circ} \mathrm{C}\right)$. A drop of the suspension was then placed on a carbon-coated $\mathrm{Cu}$ grid. In order to obtain statistically consistent information on the particle size distribution, the length of about 200 particles was measured, employing Image ${ }^{\mathrm{TM}}$ software. The composite phases analysis were investigated by X-ray powder diffraction (XRD) analysis. The XRD analysis was performed in a Bruker D8 Advance diffractometer with a $\mathrm{Cu} \mathrm{K}_{\alpha}$ radiation source operating at $30 \mathrm{kV}$ and a tube current of $25 \mathrm{~mA}$. XRD diagrams were acquired with values of $2 \theta$ from 5 to 80 , with a step size of 0.03 . The surface properties and surface area of the composite, were characterized by $\mathrm{N}_{2}$ adsorption measurements at $77 \mathrm{~K}$ using a surface area analyzer (Micromeritics Gemini 2360 instrument). The BET specific surface areas were determined by standard multipoint techniques of nitrogen adsorption. The determination of pore size was carried out by the method of BJH according to implemented software routines. Fourier transform infrared (FT-IR) spectroscopy analyses were performed using a spectrometer Nicolet Magna IRTM 550 FTIR. The determination of $\mathrm{pH}_{\mathrm{zpc}}$ of $\mathrm{TUF} / \mathrm{Fe}-\mathrm{Cu}$ nanocomposite was performed by applying the method reported on the literature [15], using a $\mathrm{pH}$ meter Conductronic $\mathrm{pH}$ 120.

\subsection{Kinetic adsorption experiments}

The influence of the contact time over an amount of organic dye removal by the TUF/Fe-Cu nanocomposite was studied through batch experiments, at a dye initial concentration of $50 \mathrm{mg} / \mathrm{L}$, adding $10 \mathrm{~mL}$ of dye solution to $10 \mathrm{mg}$ of nanocomposite. The mixture was shaken at different times at $120 \mathrm{rpm}$, and the adsorbent was separated by centrifugation and after decanted. The experiments were performed in duplicate.

To analyze the effect of dye structure three kind of dye were studied: basic dye (malachite green), acid dye (acid green 25) and azo dye (congo red). To study the effect of $\mathrm{pH}$ and temperature on MG adsorption process, the dye solutions $\mathrm{pH}$ were adjust from 2 to 12 using $0.1 \mathrm{M} \mathrm{HCl}$ and $0.1 \mathrm{M} \mathrm{NaOH}$ solutions and the temperature values were 293, 303 and $313 \mathrm{~K}$ respectively.

\subsection{Adsorption isotherms}

$10 \mathrm{mg}$ of TUF/Fe-Cu nanocomposite was put in contact with $10 \mathrm{~mL}$ at different initial concentration of dye $(30-120 \mathrm{mg} / \mathrm{L})$ stirring during equilibrium time at room temperature. The mixture was centrifuged and decanted. The malachite green dye concentrations in the solutions were determined using a UV/Vis Perking Elmer Lambda 10 ultraviolet-visible spectrophotometer to $620 \mathrm{~nm}$ as maximum wavelength. The $\mathrm{pH}$ of each solution was measured before and after the treatments. The kinetic and adsorption data of the adsorbed amount of dye at time, $\mathrm{q}_{\mathrm{t}}(\mathrm{mg} / \mathrm{g}$ of adsorbent), were obtained by Eq. (1):

$\frac{\left(C_{o}-C_{t}\right) \cdot V}{m}=q_{t}$

Where, $C_{o}(m g / L)$ is the initial dye concentration, $C_{t}(m g / L)$ is the concentration of the solution at time $t, V(L)$ is the volume of 
treated solution, and $\mathrm{m}(\mathrm{g})$ is the mass of $\mathrm{TUF} / \mathrm{Fe}-\mathrm{Cu}$ nanocomposite.

\section{Results and discussion}

\subsection{Synthesis of TUF/Fe-Cu nanocomposite}

The TUF/Fe-Cu nanocomposite was prepared by synthesizing $\mathrm{Fe}-\mathrm{Cu}$ nanostructures in-situ in an aqueous solution containing a certain amount of TUF mineral. Thus, $\mathrm{Fe}^{2+}$ and $\mathrm{Cu}^{2+}$ are sorbed or attached in TUF mineral micrometric particles (contact time), then, the main chemical reaction proceeds through reduction of iron and copper ions with sodium borohydride, according to the following stoichiometric equation

$4 \mathrm{Fe}^{2+}+4 \mathrm{Cu}^{2+}+3 \mathrm{BH}_{4}^{-}+12 \mathrm{H}_{2} \mathrm{O} \rightarrow 4 \mathrm{Fe}^{0} \mathrm{Cu}^{0}+3 \mathrm{~B}(\mathrm{OH})_{4}+24 \mathrm{H}^{+}$

The physicochemical structure (pores, voids, chemical moieties) of TUF should work as nanoreactors, as have been demonstrated for several materials [5], where the nucleation, growth, coarsening, and some times agglomeration, processes of nanostructures occur. In addition, the presence of oxygen and stirring condition in the reaction allowed the zerovalent metals became mainly $\mathrm{Fe}$ and $\mathrm{Cu}$ oxides [16] and also, under the actual reaction conditions, to generate a Fe-Cu oxides nanoparticles [13].

\section{2. $\mathrm{TUF} / \mathrm{Fe}-\mathrm{Cu}$ nanocomposite characterization}

In Fig. 1 different diffraction patterns can be seen for TUF mineral and TUF/Fe-Cu nanocomposite, which are mainly the characteristic peaks related to the basic minerals found in TUF, calcite and clinoptilolite. Besides these peaks, there are others less intense peaks corresponding to iron oxides nanoparticles. Peaks found related to copper have the lowest intensity, this may have two explanations, the first one is because the amount of copper in the bymetallic system is very low, and the second one is associated to the plausible formation of a $\mathrm{Fe}-\mathrm{Cu}$ oxide nanoparticles, in which it has already been studied by XRD that copper peaks usually do not appear [17].

TEM images of nanoparticles formed in the TUF/Fe-Cu nanocomposite, and extracted as mentioned in the experimental section, are shown in Fig. 2. As can be observed, at least two different nanostructures shapes were found, some of the particles are spherical (a), connected in chain-like structure and other have

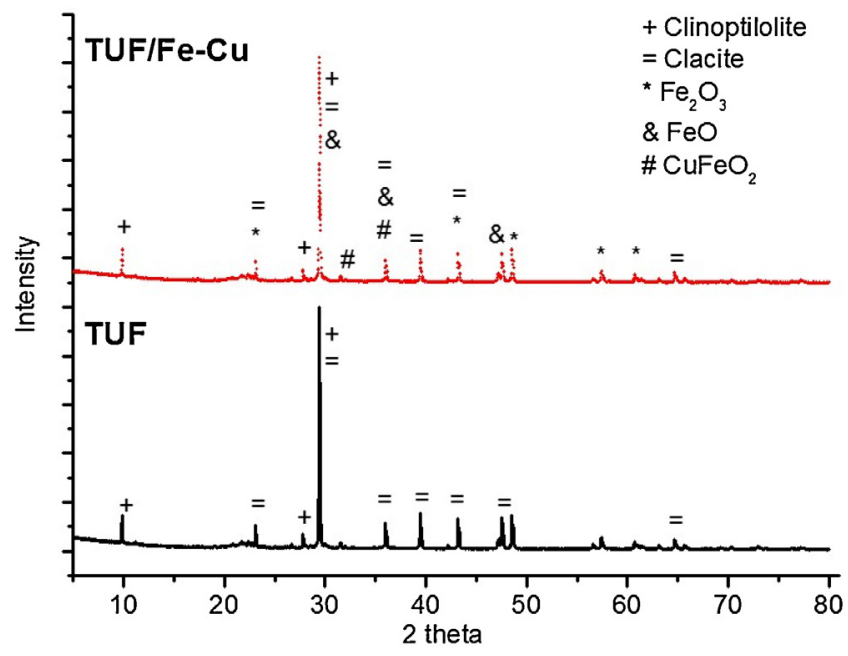

Fig. 1. XRD analysis of the TUF mineral and TUF/Fe-Cu nanocomposite.

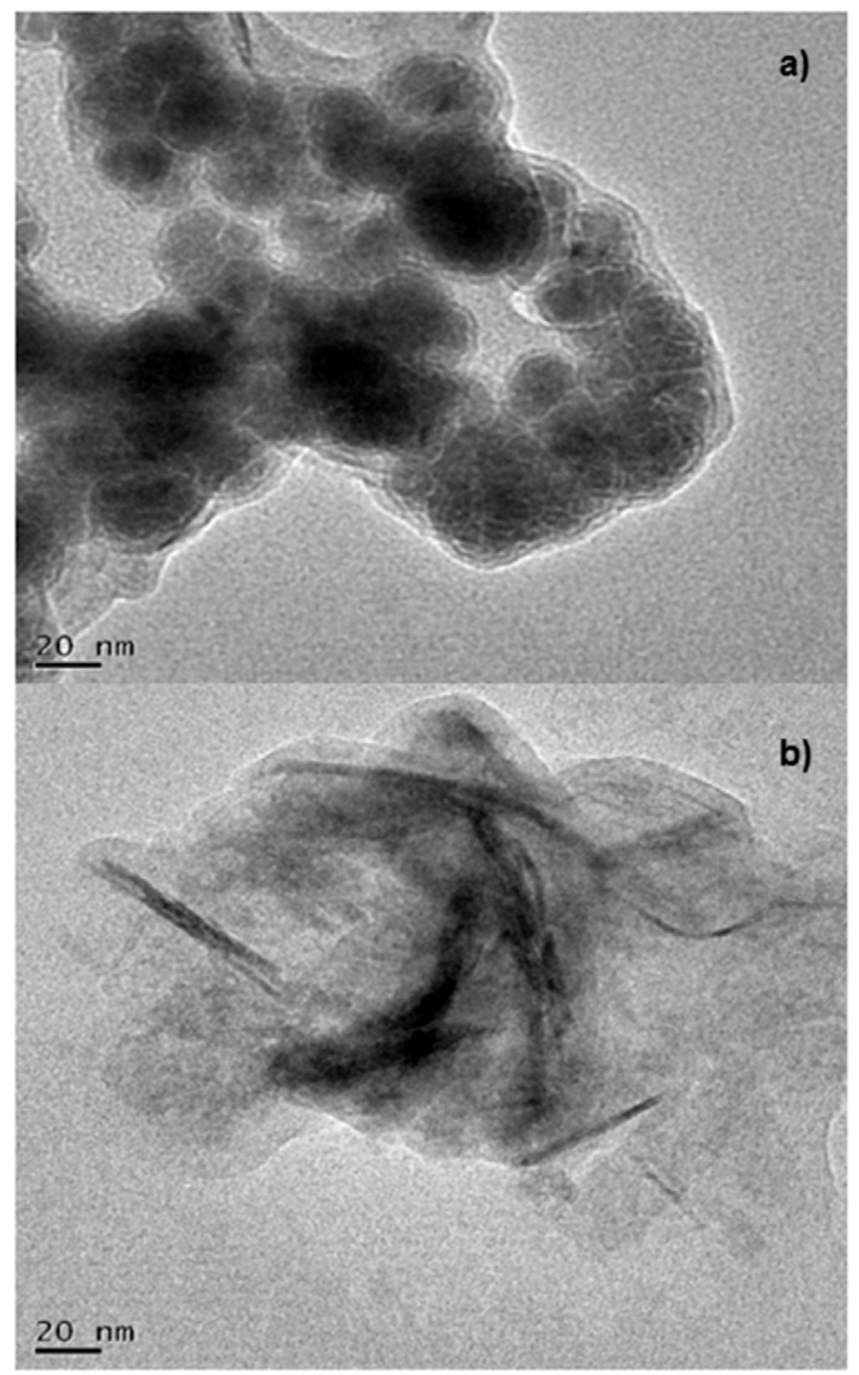

Fig. 2. TEM images of the $\mathrm{Fe}-\mathrm{Cu}$ nanostructures formed in the TUF/Fe-Cu nanocomposite.

elongated form or needle-shape (b). Also, it can be noticed that the nanoparticles tend to form agglomerates.

The size of spherical nanoparticles oscillates between 10 and $20 \mathrm{~nm}$ (Fig. 3a). For needle-like nanoparticles the dispersion of size was higher, with an the average size of $15 \mathrm{~nm}$ of length (Fig. 3b). These results are consistent with those reported in works forming similar nanocomposites using different support materials $[3,18]$. These relatively small mean sizes of the thus obtained nanoparticles can be associated to the fast way of adding to the mixture solution of the reducing agent $\left(\mathrm{NaBH}_{4}\right)$, which causes the rapid reduction rate of both metal ions to form nanoparticles fixed on TUF mineral.

The chemical composition of the TUF/Fe-Cu nanocomposite was obtained through mapping chemical and lineal profile of chemical composition from STEM analysis.

As observed in EDS maps, copper and iron moieties (Fig. 4) show similar distributions along the support material which can be associate to an homogenous distribution of the both nanoparticles on the mineral; although, iron nanostructures, accordingly to their higher concentration.

Lineal profile of chemical composition of the TUF/Fe-Cu nanocomposite (Fig. 5a and b) confirm the results obtained by TEM and EDS mapping. The intensity profiles of signals indicate the 

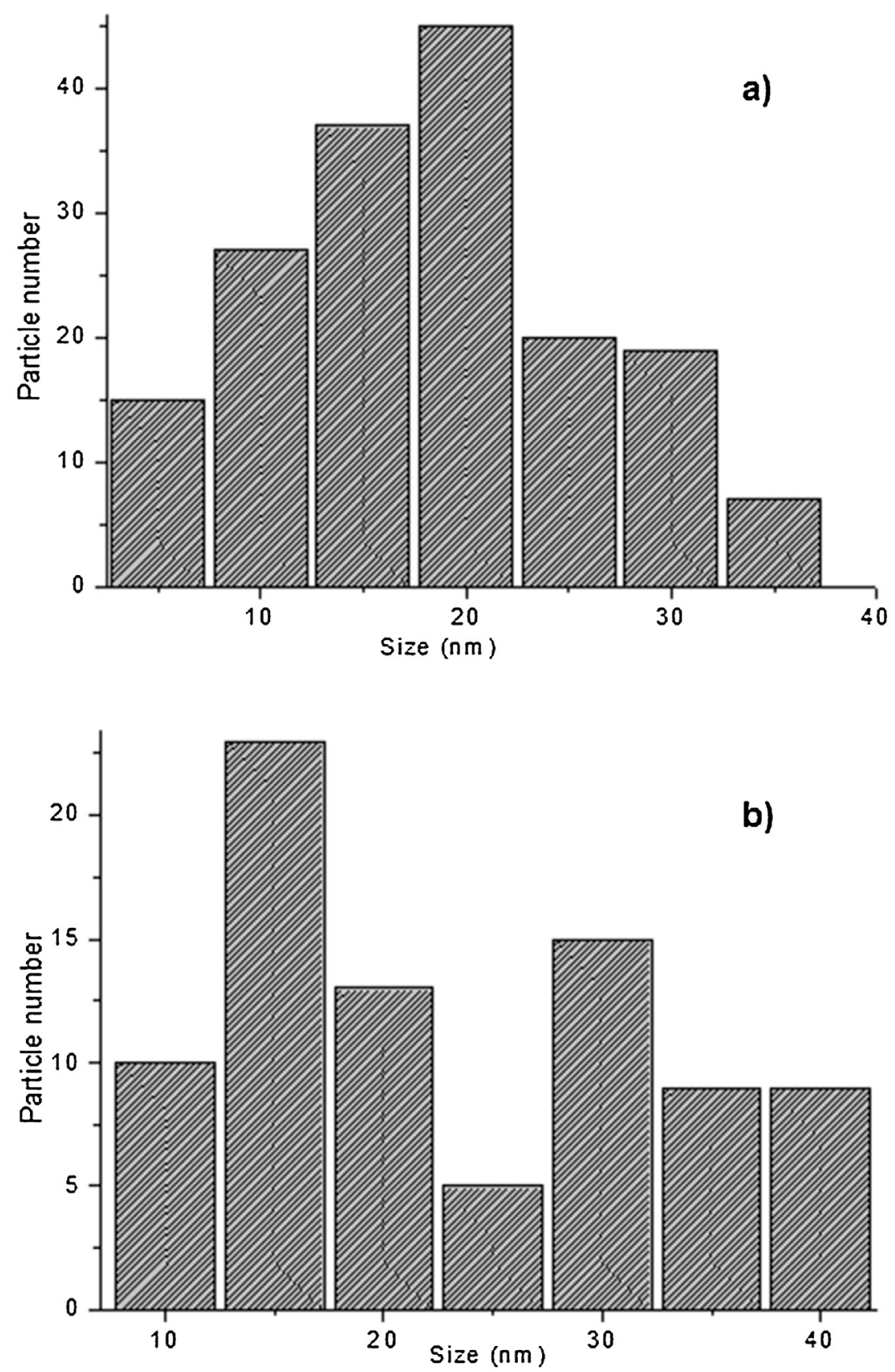

Fig. 3. Distribution of sizes for spherical (a) and needle-shape (b) Fe-Cu nanostructures in the TUF/Fe-Cu nanocomposite.

presence of iron moieties in higher concentration in contrast with the copper. These results are confirming the proportion $75-25 \mathrm{wt} . \%$ of Fe-Cu employed to synthetized to obtain the composite. The mixture of both species also can suggest the formation of $\mathrm{Fe}-\mathrm{Cu}$ oxides nanoparticles dispersed on the TUF/Fe-Cu nanocomposite in different proportions.

The nitrogen adsorption-desorption isotherm profile of the nanocomposite can be classified as type II isotherm and type $\mathrm{H} 3$ hysteresis loop according to BDDT classification [19]. This isotherm, and its hysteresis, is usually found on mesopore solids forming slit pores with nonuniform size. The plot of the pore size distribution from adsorption-desorption isotherm by BJH method confirms this idea, since the average pore diameter is $9.50 \mathrm{~nm}$ for adsorption and $1.94 \mathrm{~nm}$ for desorption. The calculated BET surface area is $9.45 \mathrm{~m}^{2} / \mathrm{g}$.

The TUF/Fe-Cu nanocomposite has a $\mathrm{pH}_{\mathrm{pzc}}$ of 9.30. Same determination for TUF only yielded a value of 9.04. Therefore, accordingly to these results, it seems that the surface of the support material was modified due to the incorporation of the Fe$\mathrm{Cu}$ oxides nanoparticles.

The composite has a rough and heterogeneous surface, with particles agglomerated of different shape and size, as can be observed in the SEM micrograph shown in Fig. 6a. The white points denoted by ellipse could be associated to metallic nanoparticles.

The micrograph after malachite green adsorption (TUF/Fe-Cu/ MG) shows a smoother surface (Fig. 6b). In comparison with the 

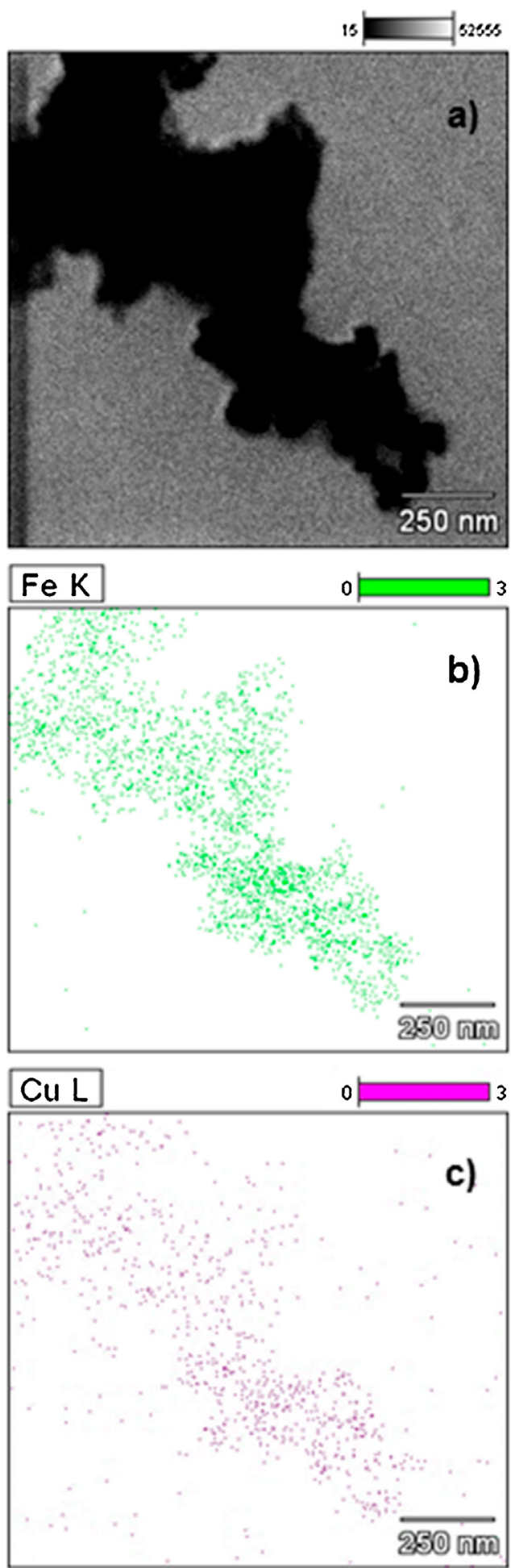

Fig. 4. EDS mapping of the TUF/Fe-Cu nanocomposite. STEM - Bright Field (BF) micrograph (a); Fe K $\alpha$ signal (b); C) Cu L $\alpha$ signal (c).

TUF/Fe-Cu nanocomposite micrographs, luminous points are not visible, which could be due to the interaction with dye molecules that can remain attached to the composite surface.

For the nanocomposite, the EDS analysis (Table 1, Fig. 6c) indicates a heterogeneous composition of alkaline, alkaline-earths and transition elements. In this case the major element is oxygen, followed by calcium, carbon, silicon, iron and copper. The biggest proportion of oxygen is due to the main phase of support material
(TUF), (calcite like $\mathrm{CaCO}_{3}$ ) and the nanoparticles oxides, according to synthesis method selected in absence of inert atmosphere. The calcium, carbon and silicon are related to chemical composition of main phase in support material. The iron and copper are related with nanoparticles added to the support material.

IR spectra of TUF mineral, TUF/Fe-Cu nanocomposite and TUF/ $\mathrm{Fe}-\mathrm{Cu} / \mathrm{MG}$, are shown in Fig. 7. TUF exhibits main bands at 1500$700 \mathrm{~cm}^{-1}$ region. These bands evidence the presence of $\mathrm{CaCO}_{3}[20]$, confirming the material's main phase. For the TUF/Fe-Cu nanocomposite, the appearance of new absorption bands about $1211.78 \mathrm{~cm}^{-1}, 1740.29 \mathrm{~cm}^{-1}$ and $2930-3010 \mathrm{~cm}^{-1}$ can be observed. Also, characteristic bands intensity of support material decrease and other disappear. All these confirm, to some extent, the chemical transformation of TUF material by the combination of surface groups with different chemical species of $\mathrm{Fe}$ and $\mathrm{Cu}$ that could be forming onto the nanostructures surface. When MG dye is adsorbed, the band intensities in the TUF/Fe-Cu nanocomposite decrease; in addition to the appearance of new bands in this spectrum, which corresponds to MG molecule, as observed in Fig. 7(b), confirms the removal of dye molecules by the TUF/Fe-Cu nanocomposite.

\subsection{Adsorption kinetics}

Adsorption kinetic is the relationship of adsorption capacity versus time; in this case, it refers to the quantification of the organic dye adsorbed in the adsorbent material from different contacting time. Fig. 8a shows the adsorption kinetic behavior for the $\mathrm{Fe}-\mathrm{Cu}$ nanostructures and for the TUF/Fe-Cu nanocomposite. For the nanostructures alone, the equilibrium time was reached at $70 \mathrm{~min}$, meanwhile for the composite the equilibrium time was reached at $160 \mathrm{~min}$. This latest time is twice higher than TUF material ( $80 \mathrm{~min})$ and nanostructures alone. It seems that the incorporation of nanoparticles in TUF interferes in the diffusion process, making the access to surface sites more difficult, which slows down the dyeadsorption process.

In order to elucidate the adsorption mechanism and potential rate controlling step of TUF/Fe-Cu nanocomposite, three kinetic models including the pseudo-first order, pseudo-second order, and intraparticle diffusion model [21] were used. These models give support information about occurrence and mechanism of adsorption on the composite. Values of correlation coefficient $\mathrm{R}^{2}$ for the $\mathrm{TUF} / \mathrm{Fe}-\mathrm{Cu}$ nanocomposite were closer to one. The value of $\mathrm{q}_{\mathrm{t}}$ experimental $\left(\mathrm{q}_{\exp }\right.$ ) was closer to the value obtained for pseudofirst order model ( $\left.\mathrm{q}_{\mathrm{cal}}\right)$. Therefore, the process was better described by pseudo-first order model (Table 2). It is, therefore, suggested that the removal of MG was carried by physisorption process, although we cannot rule out that chemical adsorption processes can occur simultaneously.

The dye adsorption process by composite particles occurs in several steps, this situation can be study using the intraparticle diffusion model. Since the intraparticle diffusion model does not satisfies the linear relationship with the experimental data, then the adsorption process may occur by two or more steps (Fig. 8b). In this case the plot gave three linear regions, attributed to the diffusion of dye molecule through the solution to the external surface of composite (I), to intraparticle diffusion with gradual equilibrium stage (II) and final equilibrium stage (III). In the graph, the plots are not linear over the whole time range, implying that more than one process is controlling the adsorption process [22]. Zones I and II can be identify as mesopores and micropores diffusion, respectively; also, zone I is similar in time range than II, indicating that the diffusion in mesopores is similar in extent to that in micropores diffusion. This agrees with the mesopores found in the composite, or mesopores close to micropores, which is confirmed by BET surface area obtained (vide supra). 


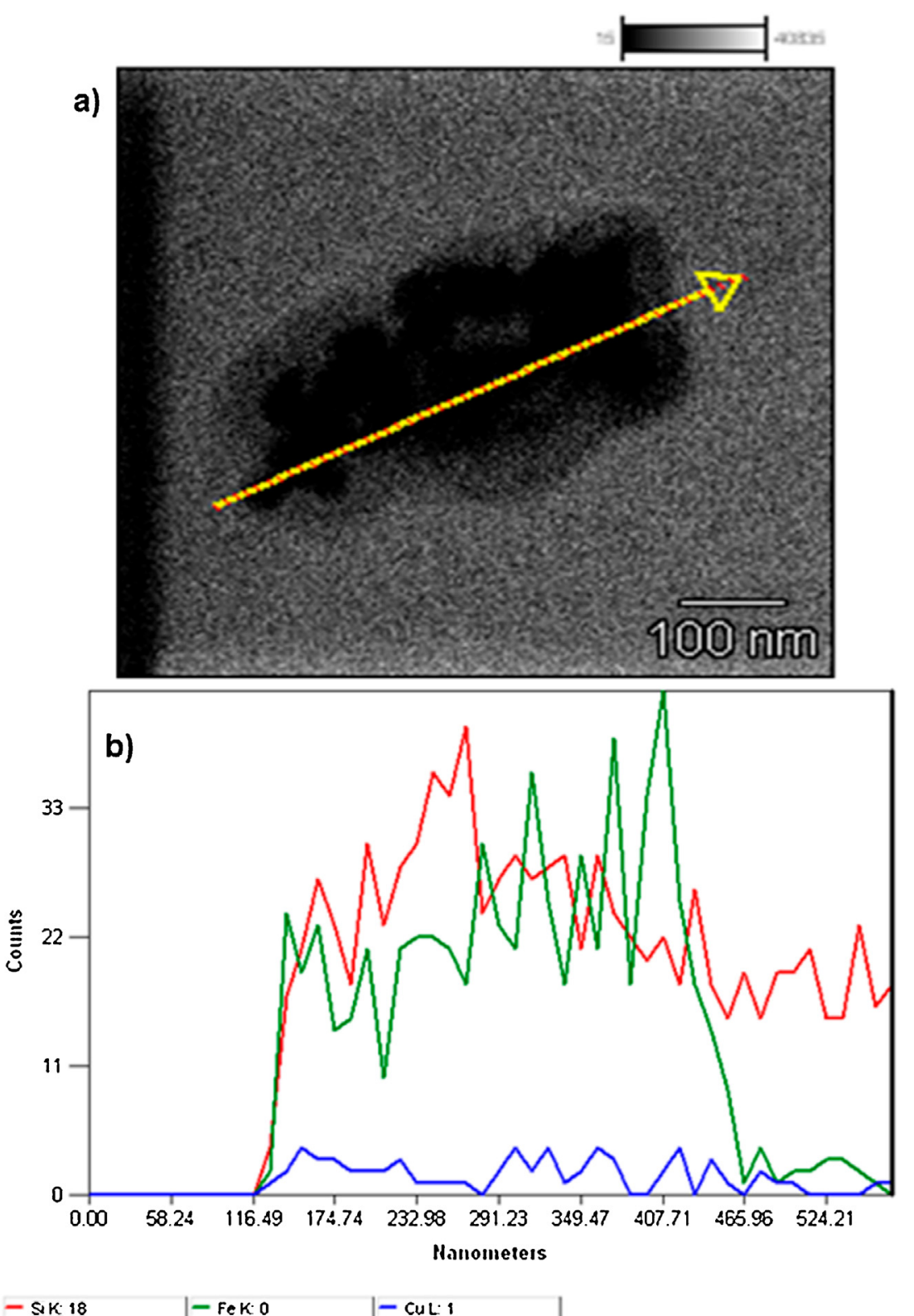

Fig. 5. STEM analysis of the TUF/Fe-Cu nanocomposite.

The results of applying kinetics models to natural material (TUF) and the TUF/Fe-Cu nanocomposite imply that incorporation of nanostructures did not modify the kinetic process. In addition, the kinetic rate constant was higher for TUF $\left(k_{2}=0.13 \mathrm{~g} / \mathrm{mg} \mathrm{min}\right)$ than for the composite $\left(k_{2}=0.03 \mathrm{~g} / \mathrm{mg} \mathrm{min}\right)$.

\subsection{Effect of $\mathrm{pH}$}

$\mathrm{pH}$ of the aqueous solution plays an important role in the characteristics of adsorbate and the adsorbents efficiency [23]. The removal of MG dye by the TUF/Fe-Cu nanocomposite from aqueous solutions increases with $\mathrm{pH}$ of the solutions because there is an increase in the adsorption capacity (Fig. 9a). The Fig. 9b indicate that the adsorption of MG dye is weak in acidic conditions. It is posibly that the removal occur through electrostatic interaction at basic $\mathrm{pH}$ or a chemical reaction between the dye molecules and the $\mathrm{TUF} / \mathrm{Fe}-\mathrm{Cu}$ nanocomposite adsorbent.
One of the components of TUF is $\mathrm{CaCO}_{3}$, in aqueous solution, carbonate ions $\left(\mathrm{CO}_{3}{ }^{2-}\right)$ are present. Under low $\mathrm{pH}$ conditions, hydrogen ions $\left(\mathrm{H}^{+}\right)$should interact with $\mathrm{CO}_{3}{ }^{2-}$ to perhaps generate $\mathrm{H}_{2} \mathrm{CO}_{3}$, avoiding thus the interaction with $\mathrm{MG}$ molecules and decreasing the dye adsorption.

$\mathrm{CO}_{3}^{2-}+\mathrm{H}^{+} \rightleftarrows \mathrm{HCO}_{3}^{-}$

$\mathrm{HCO}_{3}^{-}+\mathrm{H}^{+} \rightleftarrows \mathrm{H}_{2} \mathrm{CO}_{3}$

At a basic medium, with the presence of hydroxyl ions $\left(\mathrm{OH}^{-}\right)$, the interaction between $\mathrm{CO}_{3}{ }^{2-}$ with $\mathrm{OH}^{-}$is not posible, then the species present in aqueous solution could attract electrostatically the MG molecules promoting the removal of dye.

$\mathrm{CO}_{3}^{2-}+\mathrm{H}_{2} \mathrm{O} \rightleftarrows \mathrm{HCO}_{3}^{-}+\mathrm{OH}^{-}$ 


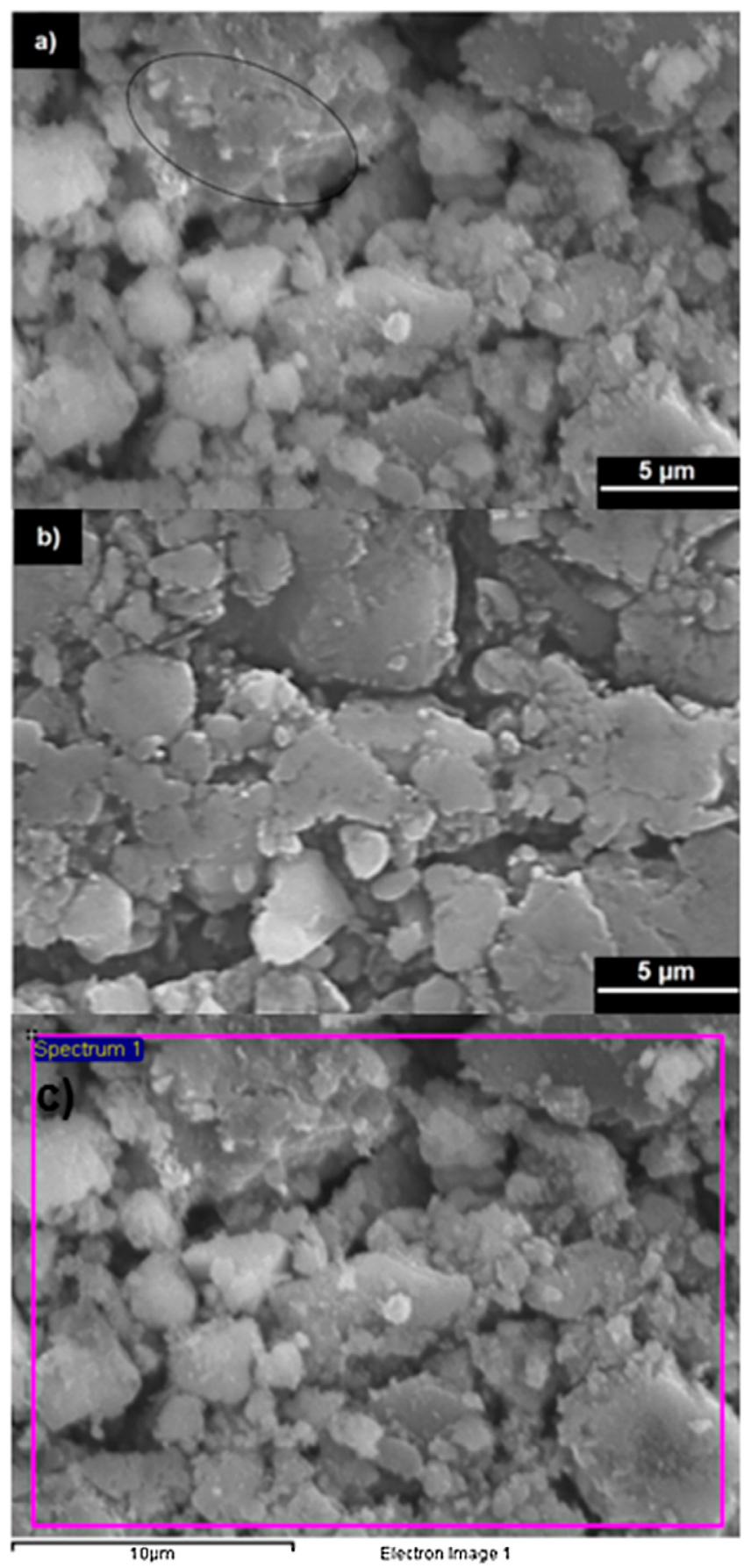

Fig. 6. SEM micrographs of TUF/Fe-Cu nanocomposite (a) and composite after malachite green dye adsorption (b; c), SEI, $20 \mathrm{kV}, \times 5000$. (For interpretation of the references to colour in this figure legend, the reader is referred to the web version of this article.)

Besides, the transformation of MG molecule to MG-carbinol molecule under basic conditions is possible (Fig. 9b) and this can promote other processes of removal like electrostatic atraction, hydrogen bond interaction and/or chemical reaction.

\subsection{Effect of temperature}

The experimental results shown in Fig. 10 demonstrates that the adsorption capacity increases when the solution temperature also augments, which indicates that the adsorption of MG dye by the TUF/Fe-Cu nanocomposite is endothermic in nature.
The process is favored for higher temperatures perhaps due to a higher mobility of the dye molecules, accordingly to the increase of the rate constant of pseudo-second order model kinetics $\left(k_{2}\right.$, Table 3) as well as of the diffusive movement.

The thermodynamic parameters were determined using Eqs. (3)-(6) (Table 4). The values of $\Delta \mathrm{H}^{\circ}$ (change in enthalpy, $\mathrm{kJ} / \mathrm{mol}$ ), $\Delta \mathrm{S}^{\circ}$ (change in entropy, $\mathrm{kJ} / \mathrm{molK}$ ) and $\mathrm{E}_{\mathrm{a}}$ (energy of activation, $\mathrm{kJ} /$ mol) were obtained from slope and intercept of $\Delta \mathrm{G}^{\circ} \mathrm{vs}$. T and $\operatorname{lnk}_{1}$ vs. $1 /$ T plot respectively [24].

$K_{c}=\frac{C_{a}}{C_{e}}$

$\Delta G^{\circ}=-R T \ln K_{C}$

$\Delta G^{\circ}=\Delta H^{\circ}-T \Delta S^{\circ}$

$\ln k_{1}=\ln A-\frac{E_{a}}{R T}$

Where $K_{c}$ is the equilibrium constant, $C_{e}$ and $C_{a}$ is the liquid and solid phase concentration at equilibrium $(\mathrm{mg} / \mathrm{L}), \mathrm{T}$ is the temperature $(\mathrm{K}), \Delta \mathrm{G}^{\circ}$ is the change in free energy $(\mathrm{kJ} / \mathrm{mol})$ and $R$ is the gas constant $(8.31 \mathrm{~J} / \mathrm{mol})$.

Generally, the adsorption process is assigned to physisorption in nature when the $\Delta G^{\circ}$ value is in the range of -20 to $0 \mathrm{~kJ} / \mathrm{mol}$, while values ranging from -400 to $-80 \mathrm{~kJ} / \mathrm{mol}$ suggests a chemisorption process [25]. The negative value of $\Delta G^{\circ}$ for the intervals of solutions temperature confirms the spontaneous nature of adsorption and the adsorption efficiency of MG dye by the $\mathrm{TUF} / \mathrm{Fe}-\mathrm{Cu}$ nanocomposite with the increase in temperature. The endothermic nature of process is confirmed by the positive value of $\Delta \mathrm{H}^{\circ}$. Moreover, the enthalpy value for an adsorption process can also be used to distinguish between chemical and physical adsorption. For chemical adsorption, values of enthalpy change range from 83 to $830 \mathrm{~kJ} / \mathrm{mol}$, while for physical adsorption they range from 8 to $40 \mathrm{~kJ} / \mathrm{mol}$. Since this value is lower than $40 \mathrm{~kJ} /$ $\mathrm{mol}$, this adsorption process can be considered as a physisorption process [26]. The value of $E_{a}$ is between 5 and $40 \mathrm{~kJ} / \mathrm{mol}$ (low values) thus, the adsorption is confirmed that occur through physisorption process [27]. The positive value of $\Delta S^{\circ}$ show that the randomness increases at the solid-solution interface during the adsorption process of MG dye.

\subsection{Effect of dye chemical structure}

In order to study the adsorption capacity of the TUF/Fe-Cu nanocomposite against other organic dyes with evident chemical differences to MG dye, we decided to perform batch experiments with red congo (CR) and acid green 25 (AG25) dyes. The equilibrium time was different in all three cases. It is highest for MG adsorption, followed by CR and the lower for AG25 (Fig. 11a). The same behavior was observed for equilibrium time.

The composite removed greater amount of the cationic dye (MG) than anionic dyes (CR and AG25). The three structures are different regarding the number of functional groups, geometry and arrangement of molecules, and also the presence of acid $\left(\mathrm{SO}_{3}{ }^{-}\right)$and basic $\left(\mathrm{CH}_{3} \mathrm{~N}^{-}\right)$groups (Fig. $11 \mathrm{~b}-\mathrm{d}$ ). Probably the molecular size of the dyes influence the efficiency of the composite dye-adsorption capacity, because the TUF/Fe-Cu nanocomposite pores are narrow, then smaller compounds that should be better adsorbed tha larger ones. In addition, cationic dyes, such as MG, can be removed more easilly using this composite because the cationic group may 
Table 1

EDS analyses of TUF mineral, TUF/Fe-Cu nanocomposite and TUF/Fe-Cu/MG.

\begin{tabular}{llll}
\hline \multirow{2}{*}{ Elements } & \multicolumn{3}{l}{ Weight percent $(\%)$} \\
\cline { 2 - 4 } & TUF & TUF/Fe-Cu & TUF/Fe-Cu/MG \\
\hline $\mathrm{C}$ & $14.70 \pm 11.72$ & $8.69 \pm 5.23$ & $18.10 \pm 6.41$ \\
$\mathrm{O}$ & $48.46 \pm 13.46$ & $49.08 \pm 6.69$ & $48.71 \pm 4.93$ \\
$\mathrm{Na}$ & $0.01 \pm 0.04$ & - & - \\
$\mathrm{Mg}$ & $0.12 \pm 0.10$ & $0.11 \pm 0.38$ & $0.19 \pm 0.31$ \\
$\mathrm{Al}$ & $1.09 \pm 1.06$ & $0.87 \pm 1.45$ & $1.42 \pm 0.64$ \\
$\mathrm{Si}$ & $9.97 \pm 8.51$ & $5.80 \pm 6.74$ & $10.42 \pm 10.20$ \\
$\mathrm{Ca}$ & $25.18 \pm 21.58$ & $27.34 \pm 11.75$ & $15.36 \pm 11.25$ \\
$\mathrm{Fe}$ & $0.47 \pm 0.46$ & $5.74 \pm 5.01$ & $4.54 \pm 2.03$ \\
$\mathrm{~K}$ & - & $0.53 \pm 1.22$ & - \\
$\mathrm{Ti}$ & - & $0.08 \pm 0.26$ & - \\
$\mathrm{Cu}$ & - & $1.76 \pm 1.56$ & $1.28 \pm 1.12$ \\
\hline
\end{tabular}

interact electrostatically with surface groups of the nanocomposite, this also has concordance with the results of the kinetic analysis for MG dye.

\subsection{Adsorption isotherms}

The adsorption experimental data were fitted with Langmuir, Freundlich, Langmuir-Freundlich and Temkin adsorption models $[28,29]$ (Table 5).

The best fit to experimental data was obtained with LangmuirFreundlich model, which indicates the adsorption process occurs by combined mechanisms on a heterogeneous surface. The value of Freundlich parameter $(1 / \mathrm{n})$ was less than one, indicating a favorable adsorption [30].

Comparing the value of maximum adsorption capacity for the $\mathrm{TUF} / \mathrm{Fe}-\mathrm{Cu}$ nanocomposite $(376.66 \mathrm{mg} / \mathrm{g}$ ) to the value of TUF
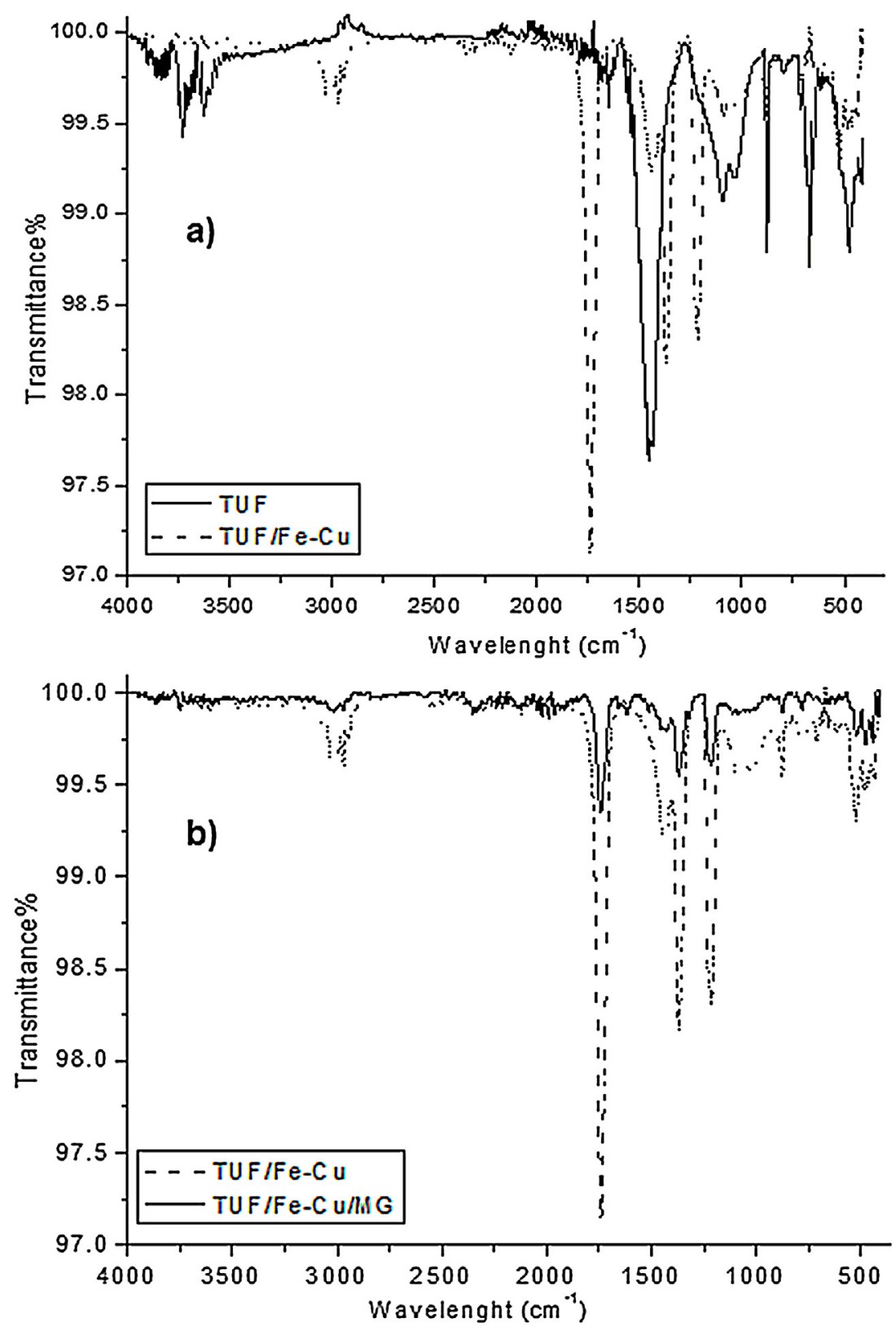

Fig. 7. FT-IR spectra of TUF (a), TUF/Fe-Cu nanocomposite (a; b) and TUF/Fe-Cu/MG (b). 

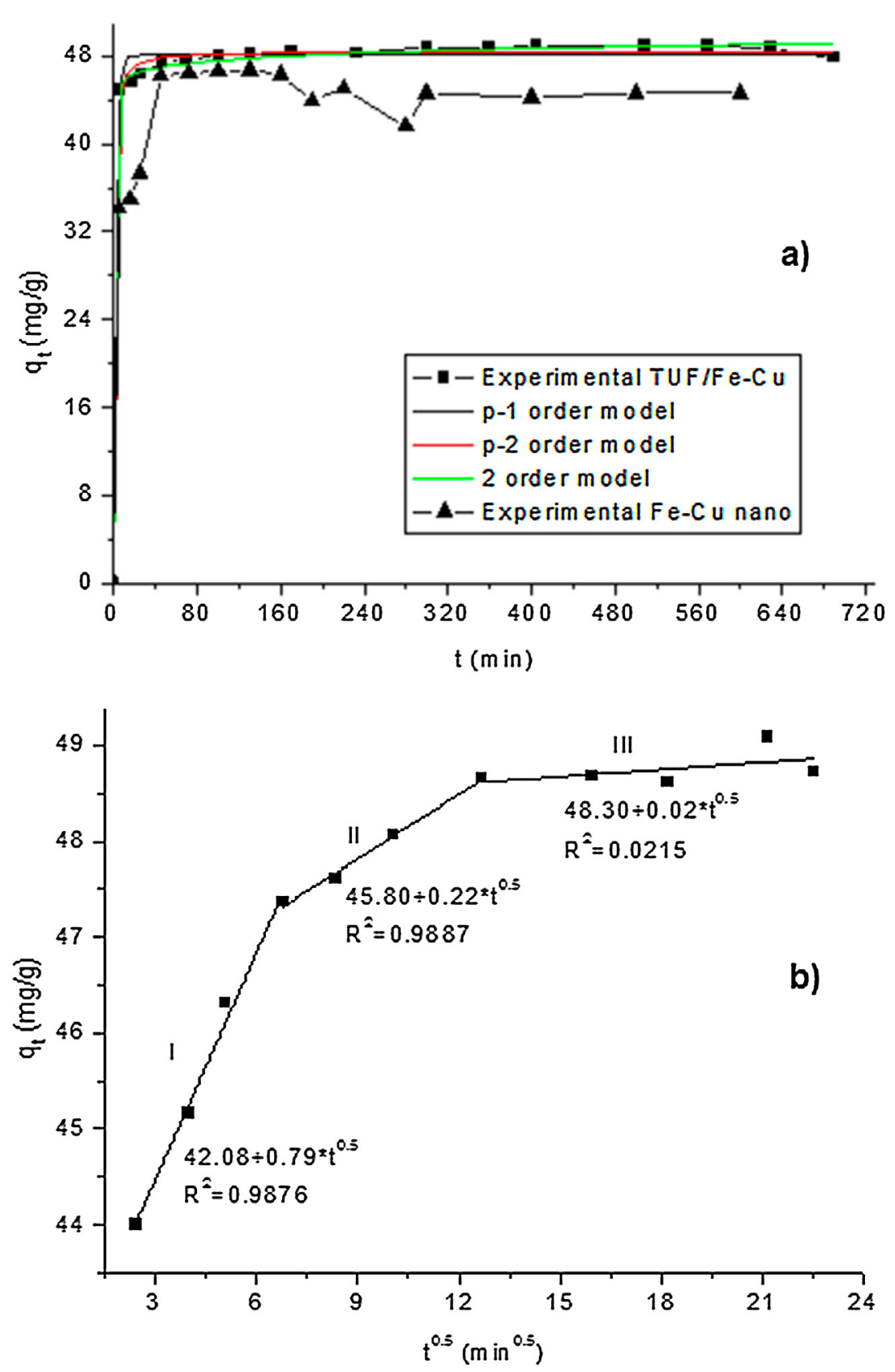

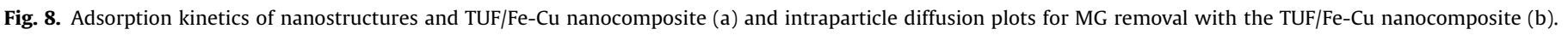

Table 2

Kinetic parameters of the MG dye adsorption on TUF/Fe-Cu nanocomposite.

\begin{tabular}{ll}
\hline Parameters & $\begin{array}{l}\mathrm{TUF} / \mathrm{Fe}-\mathrm{Cu} \\
\mathrm{q}_{\text {exp }}=48.00 \mathrm{mg} / \mathrm{g}\end{array}$ \\
\hline Pseudo-first order model & \\
$\mathrm{q}_{\mathrm{cal}}(\mathrm{mg} / \mathrm{g})$ & 47.84 \\
$\mathrm{k}_{1}\left(\mathrm{~min}^{-1}\right)$ & 0.42 \\
$\mathrm{R}^{2}$ & 0.9928 \\
& \\
Pseudo-second order model & \\
$\mathrm{q}_{\text {cal }}(\mathrm{mg} / \mathrm{g})$ & 48.47 \\
$\mathrm{k}_{2}(\mathrm{~g} / \mathrm{mg}$ min) & 0.03 \\
$\mathrm{R}^{2}$ & 0.9979 \\
& \\
$\mathrm{Intraparticle} \mathrm{diffusion} \mathrm{model}_{\mathrm{K}}\left(\mathrm{mg} / \mathrm{g}\right.$ min $\left.^{0.5}\right)$ & \\
$\mathrm{R}^{2}$ & 0.22 \\
\hline
\end{tabular}

( $212.75 \mathrm{mg} / \mathrm{g})$, the former is almost twice higher than the latter. Therefore, the presence of nanostructures favored the removal process of MG dye. The use of Fe-Cu nanostructures supported on natural material or waste material has been reported for removal of azo dye [3]. However triphenylmethane dyes (MG) have not been studied that much with nanostructures adsorbents. The results obtained from this investigation prove the effective action of TUF/ $\mathrm{Fe}-\mathrm{Cu}$ nanocomposite for removal of basic dyes, such as malachite green. In fact, the adsorption capacity of $376.66 \mathrm{mg} / \mathrm{g}$, is greater than the adsorption capacity in several systems studied for MG dye removal reported so far (Table 6).

Thus, under the same experimental conditions, the adsorption capacities of MG dye obtained for TUF, Fe-Cu nanostructures and the TUF/Fe-Cu nanocomposite are $212.75,184.47$ and $376.66 \mathrm{mg} / \mathrm{g}$, respectively. Therefore, it seems that the presence of several 

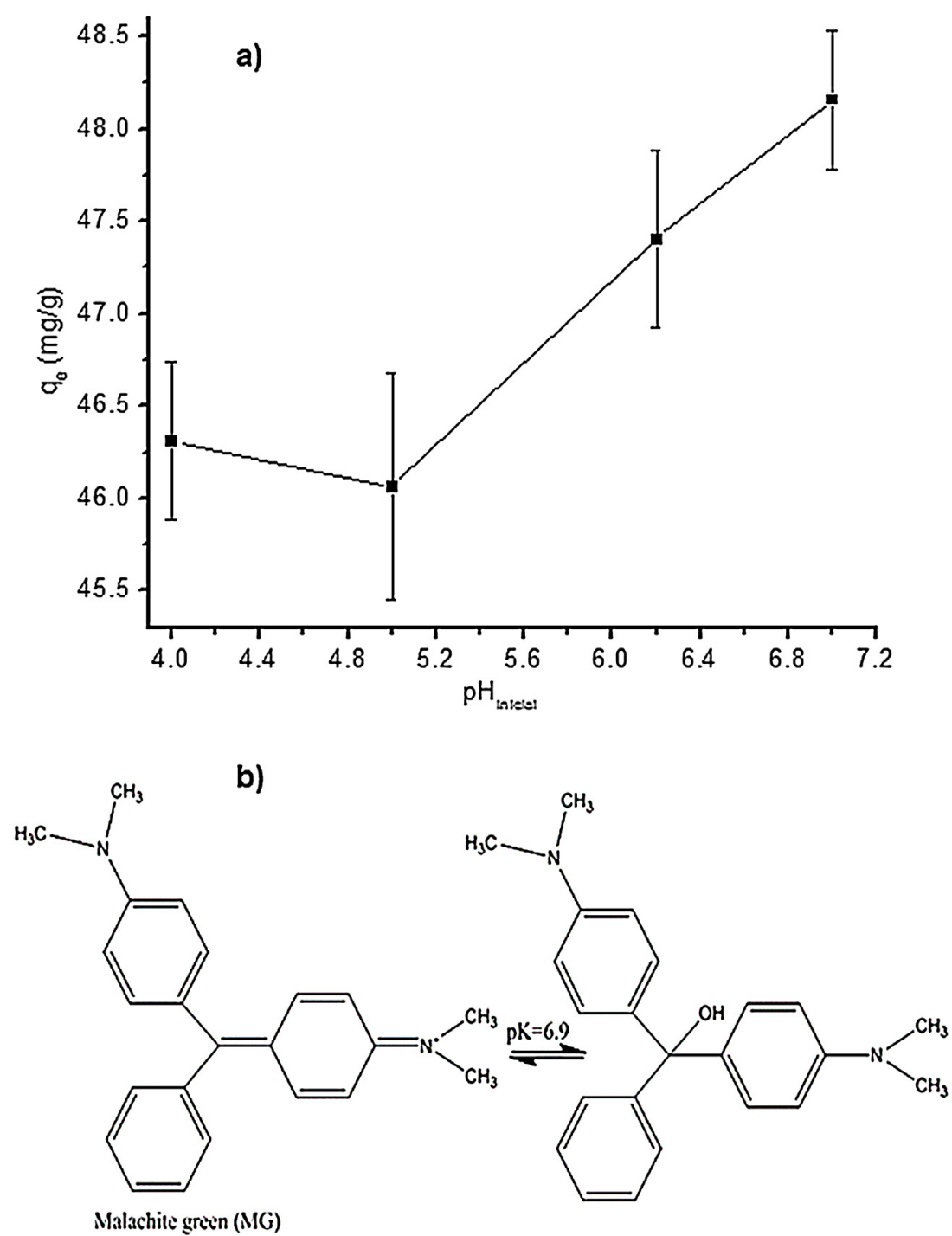

Malachite green.carbinol

Fig. 9. Effect of $\mathrm{pH}$ on the adsorption of MG dye by the TUF/Fe-Cu nanocomposite: $\mathrm{C}_{0}=50 \mathrm{mg} / \mathrm{L}, \mathrm{m}=10 \mathrm{mg}, \mathrm{t}_{\mathrm{eq}}=300 \mathrm{~min}, \mathrm{~T}=298 \mathrm{~K}$, stirring speed $=120 \mathrm{rpm}$ (a) and equilibrium structures of MG related to $\mathrm{pH}(\mathrm{b})$.

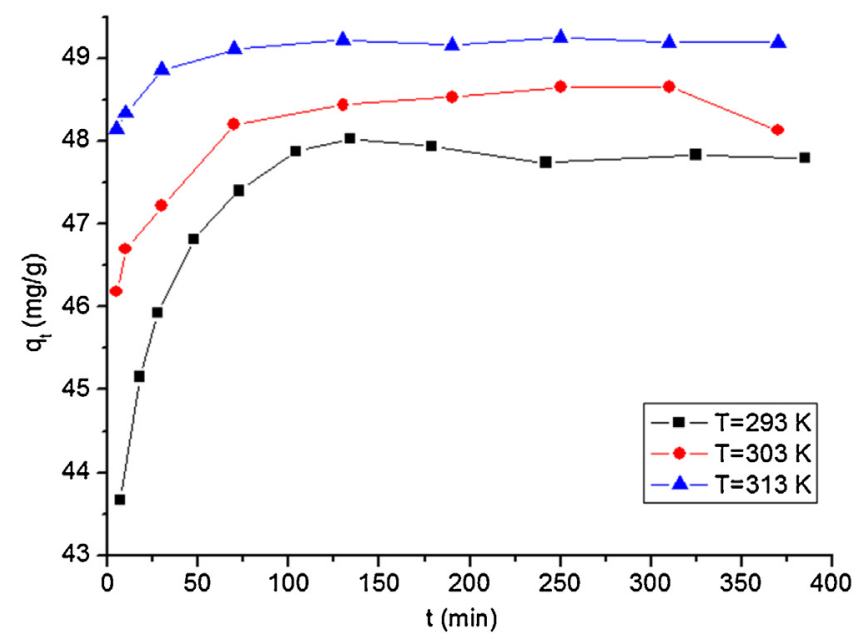

Fig. 10. Effect of temperature on the adsorption of MG dye by the TUF/Fe-Cu nanocomposite: $C_{0}=50 \mathrm{mg} / \mathrm{L}, \mathrm{m}=10 \mathrm{mg}, \mathrm{T}=293,303$ y $313 \mathrm{~K}$, stirring speed $=120$ rpm. phases in the mineral support, TUF, and the $\mathrm{Fe}-\mathrm{Cu}$ oxides nanostructures embedded, generate synergic effects increasing the removal efficiency of MG dye with this novel composite and performing the dye removal through different processes, mainly physisorption.

Table 3

Kinetic parameters of the MG dye adsorbed on TUF/Fe-Cu nanocomposite at different temperatures.

\begin{tabular}{llll}
\hline Kinetic parameters & $\mathrm{T}=298 \mathrm{~K}$ & $\mathrm{~T}=303 \mathrm{~K}$ & $\mathrm{~T}=313 \mathrm{~K}$ \\
\hline Pseudo-first order model & & & \\
$\mathrm{q}_{\mathrm{cal}}(\mathrm{mg} / \mathrm{g})$ & 47.84 & 48.09 & 49.05 \\
$\mathrm{k}_{1}\left(\mathrm{~min}^{-1}\right)$ & 0.42 & 0.63 & 0.79 \\
$\mathrm{R}^{2}$ & 0.9928 & 0.9981 & 0.9997 \\
& & & \\
Pseudo-second order model & & & \\
$\mathrm{q}_{\mathrm{cal}}(\mathrm{mg} / \mathrm{g})$ & 48.47 & 48.38 & 49.19 \\
$\mathrm{k}_{2}(\mathrm{~g} / \mathrm{mg} \mathrm{min})$ & 0.03 & 0.08 & 0.16 \\
$\mathrm{R}^{2}$ & 0.9979 & 0.9994 & 0.9999 \\
\hline
\end{tabular}


Table 4

Thermodynamic parameters for adsorption of MG dye on the TUF/Fe-Cu nanocomposite.

\begin{tabular}{|c|c|c|c|c|c|}
\hline Temperature (K) & $\Delta \mathrm{G}^{\circ}(\mathrm{kJ} / \mathrm{mol})$ & $\Delta \mathrm{H}^{\circ}(\mathrm{kJ} / \mathrm{mol})$ & $\Delta \mathrm{S}^{\circ}(\mathrm{kJ} / \mathrm{molK})$ & $\mathrm{E}_{\mathrm{a}}(\mathrm{kJ} / \mathrm{mol})$ & $\mathrm{k}_{1}\left(\min ^{-1}\right)$ \\
\hline 298 & -7.78 & 36.23 & 0.15 & 29.41 & 0.42 \\
\hline 303 & -9.72 & & & & 0.63 \\
\hline 313 & -10.79 & & & & 0.79 \\
\hline
\end{tabular}

a)

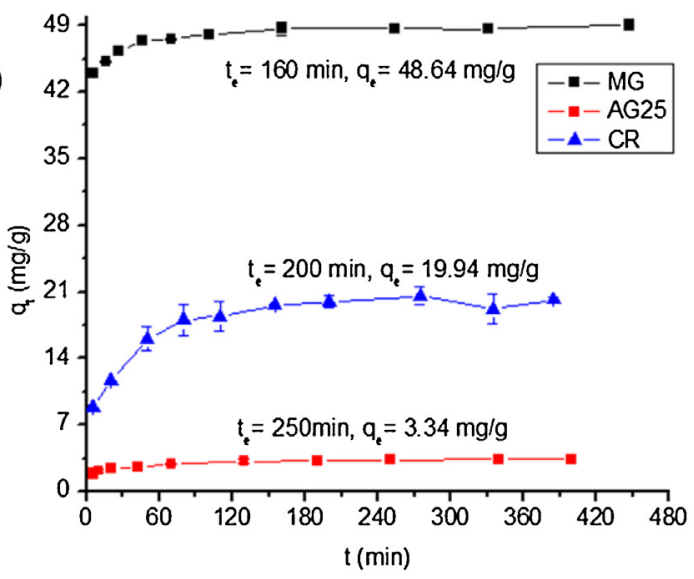

b)<smiles>Cc1ccc(Nc2ccc(Nc3ccc(C)cc3S(=O)(=O)[O-])c3c2C(=O)C2C=CC=CC2C3=O)c(S(=O)(=O)[O-])c1</smiles>

c)

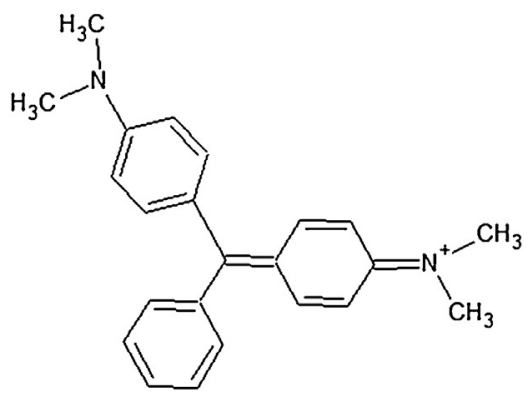

d)<smiles>Nc1c(/N=N/c2ccc(-c3ccc(/N=N/c4cc(S(=O)(=O)O[Na])c5ccccc5c4N)cc3)cc2)cc(S(=O)(=O)O)c2ccccc12</smiles>

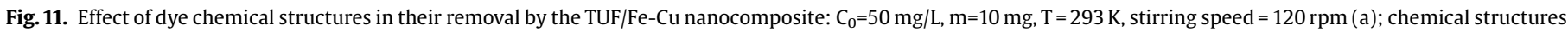
of AG25 (b), MG (c) and CR (d) dyes.

Table 5

Adsorption parameters of MG dye on TUF/Fe-Cu nanocomposite.

\begin{tabular}{|c|c|c|c|c|c|c|c|}
\hline \multicolumn{2}{|l|}{ Langmuir } & \multicolumn{2}{|l|}{ Freundlich } & \multicolumn{2}{|c|}{ Langmuir-Freundlich } & \multicolumn{2}{|l|}{ Temkin } \\
\hline $\mathrm{q}_{\max }(\mathrm{mg} / \mathrm{g})$ & 376.66 & $\mathrm{~K}_{\mathrm{F}}(\mathrm{mg} / \mathrm{g})(\mathrm{L} / \mathrm{mg})^{1 / \mathrm{n}}$ & 126.85 & $\mathrm{~K}(\mathrm{mg} / \mathrm{g})$ & 113.86 & $\mathrm{a}(\mathrm{mg} / \mathrm{g})$ & 1.07 \\
\hline $\mathrm{b}(\mathrm{L} / \mathrm{mg})$ & 0.54 & $1 / \mathrm{n}$ & 0.67 & $a(L / m g)^{n}$ & 0.095 & $\mathrm{~b}(\mathrm{mg} / \mathrm{g})$ & 176.32 \\
\hline $\mathrm{R}^{2}$ & 0.9830 & $\mathrm{R}^{2}$ & 0.9955 & $1 / \mathrm{n}$ & 0.61 & $\mathrm{R}^{2}$ & 0.9940 \\
\hline & & & & $\mathrm{R}^{2}$ & 0.9954 & & \\
\hline
\end{tabular}

In addition, ICP-OES analysis indicated that $0.5 \mathrm{ppm}$ of copper ion were desorbed. This allowed to infer that the amount of copper desorbed was fewer than the minimum value reported in the norm you referred [43].

\section{Conclusion}

Preparation of $\mathrm{Fe}-\mathrm{Cu}$ nanostructures and novel TUF/Fe-Cu nanocomposite was achieved by a simple and inexpensive chemical reduction method. SEM, TEM, XRD and FT-IR results indicated the presence of $\mathrm{Fe}-\mathrm{Cu}$ oxides nanoparticles supported or embedded on TUF material. The values of $\mathrm{pH}_{\mathrm{zpc}}$ compared to the value corresponding to TUF natural material showed the transformation of surface. TUF/Fe-Cu nanocomposite removed MG dye from aqueous solution in an efficent way. The adsorption kinetics of MG on this nanocomposite was better described by pseudo-first order model and, therefore, more than one process controlled the dye adsorption. The adsorption capacity was $376.66 \mathrm{mg} / \mathrm{g}$, which is greater than the adsorption capacity in several systems studied for MG dye removal so far. The best removal conditions were basic $\mathrm{pH}$ and higher temperature. The nanocomposite exhibited more afinity for cationic and basic dye (MG) than anionic and acid dyes (CR and AG25). According to thermodynamic results, the adsorption method is better described by a physisorption process. The low cost and the ease synthetic methodology of this novel nanocomposite, as well as its high adsorption capacity of the MG organic dye, make this composite a potential large-scale efficient material to remove organic dyes and compounds. 
Table 6

Adsorption capacity of MG dye by several adsorbents materials.

\begin{tabular}{|c|c|c|c|}
\hline Adsorbents & Initial concentration $(\mathrm{mg} / \mathrm{L})$ & $\mathrm{q}_{\mathrm{o}}(\mathrm{mg} / \mathrm{g})$ & References \\
\hline $\mathrm{NiO}$ nanoflakes & 50 & 142.08 & [31] \\
\hline Sodium alginate- $\mathrm{Fe}_{3} \mathrm{O}_{4}$ nanoparticles & $10-70$ & 47.84 & [32] \\
\hline $\mathrm{ZnO}-\mathrm{NP}-\mathrm{AC}$ & $5-30$ & 322.58 & {$[30]$} \\
\hline AC from pine sawdust & - & 370.37 & \\
\hline CAC Merck & - & 222.22 & \\
\hline Oil palm trunk fiber & - & 149.35 & \\
\hline Organically modified clay & $10-500$ & 40.48 & [33] \\
\hline $\mathrm{ZnO}-\mathrm{NP}$ & $10-40$ & 310.50 & [34] \\
\hline $\mathrm{SnO}_{2}-\mathrm{NP}$ & & 216.90 & \\
\hline Spent tea leaves & - & 256 & [35] \\
\hline Cattail & - & 196 & \\
\hline Tetraethylenepentamine-functionalized Rosa canina-L fruits activated carbon & - & 333.3 & [36] \\
\hline Organically modified hydroxyapatite & - & 188.18 & [37] \\
\hline Montmorillonite clay & - & 262.49 & [38] \\
\hline carboxylate 2 functionalized multi-walled carbon nanotubes & $50-200$ & 49.45 & [39] \\
\hline Tamarix aphylla leaves & $100-1000$ & 303.03 & [40] \\
\hline Mesoporous aluminophosphate & $100-500$ & 24.51 & [41] \\
\hline Activated Carbon from Date Palm Leaf Wastes & - & $47 \mathrm{mg} / \mathrm{g}$ & [42] \\
\hline TUF & $30-200$ & 212.75 & Previous work \\
\hline $\mathrm{TUF} / \mathrm{Fe}-\mathrm{Cu}$ & $30-200$ & 376.66 & This work \\
\hline
\end{tabular}

\section{Acknowledgements}

We thank the financial support from UAEM/2708/2013 and $3688 / 2014 /$ CIB projects. ABF is thankful to CONACYT for scholarship Grant No. 289993. We are indebted to MSc. Alejandra Núñez Pineda (elemental and IR analyses) and to MSc. Lizbeth Triana Cruz (IR analyses), both at CCIQS, UAEM-UNAM, for their technical support.

\section{References}

[1] P. Xu, G.M. Zeng, D.L. Huang C.L. Feng, S. Hu, M.H. Zhao, C. Lai, Z. Wei, C. Huang G.X. Xie, Z.F. Liux, Use of iron oxide nanomaterials in wastewater treatment: a review, Sci. Total Environ. (2012) 1-10.

[2] F. Zhang, X. Yin, W. Zhang, Development of magnetic $\mathrm{Sr}_{5}\left(\mathrm{PO}_{4}\right)_{3}(\mathrm{OH}) / \mathrm{Fe}_{3} \mathrm{O}_{4}$ nanorod for adsorption of congo red from solution, J. Alloys Compd. 657 (2016) 809-817.

[3] J. Trujillo-Reyes, M. Solache-Ríos, A.R. Vilchis-Nestor, V. Sánchez-Mendieta, A. Colín-Cruz, Fe-Ni nanostructures and C/Fe-Ni composites as adsorbent for the removal of a textile dye from aqueous solution, Water Air Soil Pollut. 223 (2012) 1331-1341.

[4] T. Wang, J. Su, X. Jin, Z. Chen, M. Megharaj, R. Naidu, Functional clay supported bimetallic nZVI/Pd nanoparticles used for removal of methyl orange from aqueous solution, J. Hazard. Mater. 262 (2013) 819-825.

[5] G. López-Téllez, R.A. Morales-Luckie, O.F. Olea-Mejía, V. Sánchez-Mendieta, J Trujillo-Reyes, V. Varela-Guerrero, A.R. Vilchis-Néstor, Nanoestructuras Metálicas: Síntesis, Caracterización Y Aplicaciones, first edition, Reverté, México, D.F, 2013.

[6] B.S. Kadua, Y.D. Sathea, A.B. Inglea, R.C. Chikatea, K.R. Patil, C.V. Rodec, Efficiency and recycling capability of montmorillonite supported Fe-Ni bimetallic nanocomposites towards hexavalent chromium remediation, Appl. Catal. B: Environ. 104 (2011) 407-414.

[7] F. Sadat, C. Falamaki, Zero valent nano-sized iron/clinoptilolite modified with zero valent copper for reductive nitrate removal, Process Saf. Environ. Protect. 91 (2012) 304-310.

[8] L. Yuhan, M. Long, P. Hu, Y. Chen, J. Huang, J. Hazard. Mater. 264 (2014) 195202.

[9] A.R. Vilchis-Nestor, J. Trujillo-Reyes, J.A. Colín-Molina, V. Sánchez-Mendieta, M. Avalos-Borja, Biogenic silver nanoparticles on carbonaceous material from sewage sludge for degradation of methylene blue in aqueous solution, Int. J. Environ. Sci. Technol. 11 (2014) 977-986.

[10] M. Forbes, R. Vogwill, K. Onton, A characterisation of the coastal tufa deposits of south-west Western Australia, Sediment. Geol. 232 (2012) 52-65.

[11] C. Jiao, Y. Wang, M. Li, Q. Wu, C. Wang, Z. Wang, Synthesis of magnetic nanoporous carbon from metal-organic framework for the fast removal of organic dye from aqueous solution, J. Magn. Magn. Mater. 407 (2016) 24-30.

[12] L. Luo, C. Dai, A. Zhang, J. Wang, M. Liu, C. Song, X. Guo, A facile strategy for enhancing FeCu bimetallic promotion for catalytic phenol oxidation, Catal. Sci. Technol. 5 (2015) 3159-3165.

[13] J. Trujillo-Reyes, V. Sánchez-Mendieta, M.J. Solache-Ríos, A. Colín-Cruz, Obtención y caracterización de un composito de carbón activado y una nanoaleación de Fe/Cu como adsorbente, Rev. Latinoam. Rec. Nat. 4 (2008) $116-121$.
[14] J. Trujillo-Reyes, V. Sánchez-Mendieta, A. Colín-Cruz, Removal of remazol yellow from aqueous solution using $\mathrm{Fe}-\mathrm{Cu}$ and $\mathrm{Fe}-\mathrm{Ni}$ nanoscale oxides and their carbonaceous composites, Environ. Technol. 33 (2012) 545-554.

[15] P. Faria, J. Órfão, M. Pereira, Adsorption of anionic and cationic dyes on activated carbons with different surface chemistries, Water Res. 38 (2004) 2043-2052.

[16] R.A. Morales-Luckie, Formación De Nanopartículas Fe-Cu: Su Caracterización Microestructural Y Determinación De Sus Propiedades Magnéticas. Tesis De Doctorado, Universidad Autónoma del Estado de México, Facultad de Química, Toluca, México, 2009.

[17] R.A. Morales-Luckie, V. Sanchez-Mendieta, J.A. Arenas-Alatorre, R. LópezCastañares, J.L. Perez-Mazariego, V. Marquina-Fabrega, R. Wayne Gómez, Onestep aqueous synthesis of stoichiometric Fe-Cu nanoalloy, Mater. Lett. 62 (2008) 4195-4197.

[18] A.D. Bokare, R.C. Chikate, C.V. Rode, K.M. Paknikar, Iron-nickel bimetallic nanoparticles for reductive degradation of azo dye Orange $G$ in aqueous solution, Appl. Catal. B: Environ. 79 (2008) 270-278.

[19] M. Kruk, M. Jaroniec, K.P. Gadkaree, Nitrogen adsorption studies of novel synthetic active carbons, J. Colloid Interface Sci. 192 (1997) 250-256.

[20] N.V. Vagenas, A. Gatsouli, C.G. Kontoyannis, Quantitative analysis of synthetic calcium carbonate polymorphs using FT-IR spectroscopy, Talanta 59 (2003) 831-836.

[21] A. Blanco-Flores, A. Colín-Cruz, E. Gutiérrez-Segura, V. Sánchez-Mendieta, D.A. Solís-Casados, M.A. Garrudo-Guirado, R. Batista-González, Efficient removal of crystal violet dye from aqueous solutions by vitreous tuff mineral, Environ. Technol. 35 (2014) 1508-1519.

[22] V.S. Mane, P.V. Babu, Studies on the adsorption of Brilliant Green dye from aqueous solution onto low-cost $\mathrm{NaOH}$ treated saw dust, Desalination 273 (2011) 321-329.

[23] L. Hu, Z. Yang, L. Cui, Y. Li, H.H. Ngo, Y. Wang, Q. Wei, H. Ma, L. Yan, B. Du, Fabrication of hyperbranched polyamine functionalized graphene for highefficiency removal of $\mathrm{Pb}(\mathrm{II})$ and methylene blue, Chem. Eng. J. 287 (2016) 545556.

[24] D. Wang, L. Liu, X. Jiang, J. Yu, X. Chen, Desorption and removal of malachite green from aqueous solution using magnetic B-cyclodextrin-graphene oxide nanocomposites as adsorbents, Colloids Surf. A: Physicochem. Eng. Aspects 466 (2015) 166-173.

[25] P. Sharma, N. Hussain, D.J. Borah, M.R. Das, Kinetics and adsorption behavior of the methyl blue at the graphene oxide/reduced graphene oxide nanosheet_water interface: a comparative study, J. Chem. Eng. Data 58 (2013) 3477-3488.

[26] A.A. Jalil, S. Triwahyono, M.R. Yankob, Z.Z.A. Azmi, N. Sapawe, N.H.N. Kamaredin, H.D. Setiabudi, N.F. Jaafar, S.M. Sidik, S.H. Adam, B.H. Hameed, Utilization of bivale shell-treated Zea mays L. (maize) husk leaf as a low cost biosorbent for enhanced adsorption of malachite green, Bioresour. Technol. 120 (2012) 218-224.

[27] R.K. Gautam, V. Rawat, S. Banerjee, M.A. Sanroman, S.K. Singh, M.C. Chattopadhyaya, Synthesis of bimetallic Fe-Zn nanoparticles and its application towards adsorptive removal of carcinogenic dye malachite green and Congo red in water, J. Mol. Liq. 212 (2015) 227-236.

[28] A.M. Soliman, H.M. Elwy, T. Thiemann, Y. Majedi, F.T. Labata, N.A.F. AlRawashdeh, Removal of $\mathrm{Pb}(\mathrm{II})$ ions from aqueous solutions by sulphuric acidtreated palm tree leaves, J. Taiwan Inst. Chem. Eng. 58 (2016) 264-273.

[29] B. Mi-Hwa, I.C. Olakitan, O. Se-Jin, K. Dong-Su, Removal of Malachite Green from aqueous solution using degreased coffee bean, J. Hazard. Mater. 176 (2010) 820-828. 
[30] M. Ghaedi, A. Ansari, M. Habibi, A. Asghari, Removal of malachite green from aqueous solution by zinc oxide nanoparticle loaded on activated carbon: kinetics and isotherm study, J. Ind. Eng. Chem. 20 (2014) 17-28.

[31] A.B. Wei, H. Liu, Y. Zhao, W. Chen, Y. Wang, H. Mab, S. Yang Synthesis and formation mechanism of flowerlike architectures assembled from ultrathin $\mathrm{NiO}$ nanoflakes and their adsorption to malachite green and acid red in water, Chem. Eng. J. 239 (2014) 141-148.

[32] A. Mohammadi, H. Daemi, B. Mehdi, Fast removal of malachite green dye using novel superparamagnetic sodium alginate-coated $\mathrm{Fe}_{3} \mathrm{O}_{4}$ nanoparticles, Int. J. Biol. Macromol. 69 (2014) 447-455.

[33] S. Arellano-Cárdenas, S. López-Cortez, M. Cornejo-Mazón, J.C. MaresGutiérrez, Study of malachite green adsorption by organically modified clay using a batch method, Appl. Surf. Sci. 280 (2013) 74-78.

[34] K.Y. Kumar, H.B. Muralidhara, Y.A. Nayaka, J. Balasubramanyam, H. Hanumanthappa, Low-cost synthesis of metal oxide nanoparticles and their application inadsorption of commercial dye and heavy metal ion in aqueous solution, Powder Technol. 246 (2013) 125-136.

[35] H. Saygılı, F. Güzel, Performance of new mesoporous carbon sorbent prepared from grape industrial processing wastes for malachite green and congo red removal, Chem. Eng. Res. Des. 100 (2015) 27-38.

[36] M. Ghasemi, S. Mashhadi, M. Asif, I. Tyagi, S. Agarwal, V.K. Gupta, Microwaveassisted synthesis of tetraethylenepentamine functionalized activated carbon with high adsorption capacity for Malachite green dye, J. Mol. Liq. 213 (2016) $317-325$.
[37] A.A. El-Zahhar, N.S. Awwad, Removal of malachite green dye from aqueous solutions using organically modified hydroxyapatite, J. Environ. Chem. Eng. 4 (2016) 633-638.

[38] B.A. Fil, Isotherm, kinetic, and thermodynamic studies on the adsorption behavior of malachite green dye onto montmorillonite clay, Part. Sci. Technol: Int. J. 34 (2016) 118-126.

[39] H. Sadegh, R. Shahryari-Ghoshekandi, S. Agarwal, I. Tyagi, M. Asif, V.K. Gupta, Microwave-assisted removal of malachite green by carboxylate functionalized multi-walled carbon nanotubes: kinetics and equilibrium study, J. Mol. Liq. 206 (2015) 151-158.

[40] M.A. Ackacha, M. Drmoon, Adsorption of malachite green dye onto nove adsorbent: Tamarix aphylla leaves, international conference on transport, Environ. Civil Eng. (2012) 141-145.

[41] C. Kannan, K. Muthuraja, M.R. Devi, Hazardous dyes removal from aqueous solution over mesoporous aluminophosphate with textural porosity by adsorption, J. Hazard. Mater. 244-245 (2013) 10-20.

[42] Y. Majedi, E. Alhilali, M. Al Nehayan, A. Rashed, S.S. Ali, N. al Rawashdeh, T Thiemann, A. Soliman, Treatment of dye-loaded wastewater with activated carbon from date palm leaf wastes, The 4th World Sustainability Forum 2014 Glyph2Conference Proceedings Paper (2014). http://www.sciforum.net/ conference/wsf-4.

[43] Norma de Calidad Ambiental y de Descarga de Efluentes: Recurso Agua (NCADE). LIBRO VI ANEXO 1, https://www.elaw.org/system/files/NCADE.doc. 